\title{
Grab what you can - an evaluation of spatial replication to decrease heterogeneity in sediment eDNA metabarcoding
}

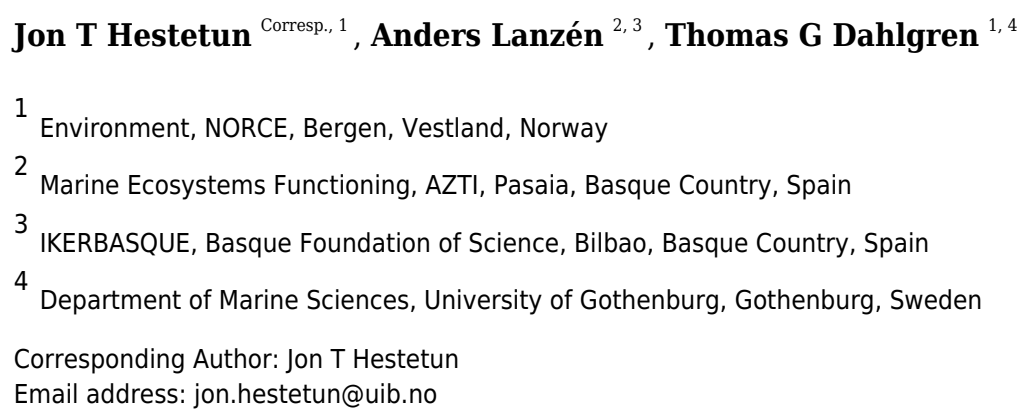

Environmental DNA methods such as metabarcoding have been suggested as possible alternatives or complements to the current practice of morphology-based diversity assessment for characterizing benthic communities in marine sediment. However, the source volume used in sediment eDNA studies is several magnitudes lower than that used in morphological identification. Here, we used data from a North Sea benthic sampling station to investigate to what extent metabarcoding data is affected by sampling bias and spatial heterogeneity. Using three grab parallels, we sampled five separate sediment samples from each grab. We then made five DNA extraction replicates from each sediment sample. Each extract was amplified targeting both the 18S SSU rRNA V1-V2 region for total eukaryotic composition, and the cytochrome c oxidase subunit I (COI) gene for metazoans only. In both datasets, extract replicates from the same sediment sample were significantly more similar than different samples from the same grab, in spite of the later comparison using pooled extraction replicates in order to compensate for sampling effect and local sediment sample heterogeneity. Further, samples from different grabs were less similar than those from the same grab for 18S. Interestingly, this was not true for COI metabarcoding, where the differences within the same grab were similar to the differences between grabs. We also investigated how much of the total identified richness could be covered by extract replicates, individual sediment samples and all sediment samples from a single grab, as well as the variability of Shannon diversity and, for COI, macrofaunal biotic indices indicating environmental status. These results were largely consistent with the beta diversity findings, and show that total eukaryotic diversity can be well represented using $18 \mathrm{~S}$ metabarcoding with a manageable number of biological replicates. Based on these results, we strongly recommend the combination of different parts of the surface of single grabs for eDNA extraction as well as several grab replicates, or 
alternatively or box cores or similar. This will dilute the effects of dominating species and increase the coverage of alpha diversity. COI-based metabarcoding consistency was found to be lower compared to $18 \mathrm{~S}$, but COI macrofauna-based indices were more consistent than direct $\mathrm{COI}$ alpha diversity measures 


\section{Grab what you can - an evaluation of spatial}

2 replication to decrease heterogeneity in sediment

3 eDNA metabarcoding

4

5 Jon T. Hestetun ${ }^{1}$, Anders Lanzén ${ }^{2,3}$, Thomas G. Dahlgren ${ }^{1,4}$

6

$7 \quad{ }^{1}$ NORCE Environment, NORCE Norwegian Research Centre, Bergen, Norway

$8 \quad{ }^{2}$ AZTI, Marine Research, Basque Research and Technology Alliance. Herrera Kaia, Portualdea

9 z/g, E-20110 Pasaia (Gipuzkoa), Spain,

10 '3KERBASQUE, Basque Foundation for Science, E-48011 Bilbao

$11{ }^{4}$ Department of Marine Sciences and Gothenburg Global Biodiversity Centre (GGBC) University

12 of Gothenburg, Box 463, 40530 Göteborg, Sweden

13

14 Corresponding Author:

15 Jon Thomassen Hestetun ${ }^{1}$

16 Nygårdsgaten 112, 5008 Bergen, Norway

17 Email address: jhes@norceresearch.no 


\section{Abstract}

19 Environmental DNA methods such as metabarcoding have been suggested as possible

20 alternatives or complements to the current practice of morphology-based diversity assessment for

21 characterizing benthic communities in marine sediment. However, the source volume used in sediment eDNA studies is several magnitudes lower than that used in morphological identification. Here, we used data from a North Sea benthic sampling station to investigate to what extent metabarcoding data is affected by sampling bias and spatial heterogeneity. Using three grab parallels, we sampled five separate sediment samples from each grab. We then made five DNA extraction replicates from each sediment sample. Each extract was amplified targeting both the 18S SSU rRNA V1-V2 region for total eukaryotic composition, and the cytochrome c oxidase subunit I (COI) gene for metazoans only. In both datasets, extract replicates from the same sediment sample were significantly more similar than different samples from the same grab, in spite of the later comparison using pooled extraction replicates in order to compensate for sampling effect and local sediment sample heterogeneity. Further, samples from different grabs were less similar than those from the same grab for $18 \mathrm{~S}$. Interestingly, this was not true for COI metabarcoding, where the differences within the same grab were similar to the differences between grabs. We also investigated how much of the total identified richness could be covered by extract replicates, individual sediment samples and all sediment samples from a single grab, as well as the variability of Shannon diversity and, for COI, macrofaunal biotic indices indicating environmental status. These results were largely consistent with the beta diversity findings, and show that total eukaryotic diversity can be well represented using $18 \mathrm{~S}$ metabarcoding with a manageable number of biological replicates. Based on these results, we strongly recommend the combination of different parts of the surface of single grabs for eDNA extraction as well as several grab replicates, or alternatively or box cores or similar. This will dilute the effects of dominating species and increase the coverage of alpha diversity. COI-based metabarcoding consistency was found to be lower compared to $18 \mathrm{~S}$, but COI macrofauna-based indices were more consistent than direct COI alpha diversity measures. 


\section{Introduction}

47 Ecological analyses of community structure in soft bottom marine benthos are commonly done

48 by sieving grab or box corer samples. Using this method, specimens are manually separated from 49 remaining sediment at a given mesh size fraction, creating a species list based on taxonomic 50 identification of each recovered organism (ISO 2014). However, this approach is relatively time 51 consuming. It also relies on access to specialized taxonomic expertise and good local species 52 descriptions, and omits ecologically important meiofauna and microorganisms from the analysis 53 (Schander \& Willassen 2005). For these reasons, methods based on environmental DNA 54 (eDNA), such as metabarcoding, have long been considered as an attractive alternative for 55 characterization of benthic communities (e.g. Aylagas et al. 2016; Baird \& Hajibabaei 2012; 56 DiBattista et al. 2020; Faria et al. 2018; Lanzén et al. 2016).

57

58

59

60

61

62

63

64

65

66

67

68

69

70

71

72

73

74

75

76

77

78

79

80

81

82

83

84

While metabarcoding has many potential advantages, the methodology employed at all steps in sampling, processing and analysis greatly influences study results (Cristescu \& Hebert 2018; Kelly et al. 2019; Zinger et al. 2019), and though a number of studies have investigated the effects of e.g. sampling design (Penton et al. 2016; Zhou et al. 2011), extraction protocol (Brannock \& Halanych 2015; Djurhuus et al. 2017; Lekang et al. 2015; Pearman et al. 2020), primer choice (Alberdi et al. 2018; Andújar et al. 2018; Leasi et al. 2018; Leray \& Knowlton 2017; Piñol et al. 2019; Tang et al. 2012; Weigand \& Macher 2018), reference barcode database coverage (Hestetun et al., 2020) and processing (Smith \& Peay 2014), sizable knowledge gaps remain. Robust sampling designs are required to win acceptance for the method from management bodies (Roussel et al. 2015) and are also a prerequisite for reproducibility, which was recently found to be low in many terrestrial and freshwater eDNA barcoding studies (Dickie et al. 2018).

For eDNA that is extracted directly from sediments, an area of specific concern is the amount of source material that is necessary for adequate community characterization. When grab or core samples are processed for morphological analysis, a relatively large volume of sediment is typically sieved at a certain mesh size (commonly 0.25 to $1 \mathrm{~mm}$ ). A van Veen grab recovers around 15-20 liter of sediment and a USNEL box corer more than 100 liters. Thus, morphological community analysis is based on the captured community from a comparatively large sample, even when considering that most of the captured organisms are found closer to the sediment surface. On the other hand, eDNA extraction is limited to subsampling a total source volume that is several magnitudes lower, typically measured in grams. At this scale, the heterogeneous distribution of extracellular DNA, mixed with smaller organisms in the source sediment introduces a strong random sampling effect. This raises the question of to which degree the source material used for eDNA studies can adequately represent the biological community captured by the total grab or core volume, not to mention the sampling locality itself (Lanzén et al. 2017; Nascimento et al. 2018). 
85 In the case of coastal or shelf depth morphological sampling, 2-5 van Veen grab replicates are 86 often used to account for spatial heterogeneity of macrofauna at meter-scale (Hatlen et al. 2019; 87 NS 2009). For eDNA sampling, different levels of spatial heterogeneity can be expected from

88 89 90

91 92 93 94 95 96 97 98 99

100

101

102

103

104

105

106

107

108

109

110

111

112

113

114

115

116

117

118

119

120

121

122

123

124 smaller scales within a grab (millimeters to centimeters), to the intermediate meter scale, at which grab replicates can be taken. Furthermore, the relative extent of this variability can be expected to be different in microorganisms compared to metazoans. DNA extraction replicates are typically used to account for heterogeneous distribution, and a handful of studies have investigated the incremental increase in observed diversity with additional extraction replicates or sediment volume (Brannock \& Halanych 2015; Lanzén et al. 2017; Nascimento et al. 2018). Less attention has been given to investigating the relative effect on data variability at different levels of spatial distance, such as within and between replicate grab samples from the same station.

As indicated previously by e.g. Lanzén et al. (2017), the effect of eDNA patchiness is likely more pronounced for meio- and macrofauna compared to single celled organisms. Hence, for metazoan metabarcoding studies using e.g. the COI marker, a common strategy is to recover the animals from the sediment prior to DNA extraction (e.g. Atherton \& Jondelius 2020; Elbrecht \& Leese 2015; Faria et al. 2018; Fonseca et al. 2010; He et al. 2021; Lejzerowicz et al. 2015). Conversely, when extracting eDNA directly from sediment, it's more common to use molecular markers that target microorganisms, such as the eukaryotic $18 \mathrm{~S}$ rRNA or the prokaryotic $16 \mathrm{~S}$ rRNA genes (e.g. Guardiola et al. 2016; Keeley et al. 2018; Lanzén et al. 2016; Lanzén et al. 2020; Sinniger et al. 2016; Stoeck et al. 2018). In several recent sediment extract studies using multiple markers, however, ribosomal markers have been supplemented with e.g. COI with promising results (Atienza et al. 2020; Laroche et al. 2020; Macher et al. 2018; Mauffrey et al. 2020). These studies suggest that sediment extracts may provide useful results despite a potential increase in spatial heterogeneity, which is significant as direct sediment extraction is a faster approach than separating organisms from the sediment, and thus especially suitable when processing a large number of samples for e.g. marine monitoring purposes.

Here, we conducted a comparative experiment with samples from three grab parallels at one North Sea sediment monitoring station located in the general vicinity of an offshore oil drilling platform. The sampling design was chosen from a practical perspective, including both sediment volume and spatial distance as parameters of interest: Metabarcoding sampling and data analysis was performed at three spatial scales: A) comparison of single DNA extraction replicates from one sediment sample from each grab (extract reproducibility), B) comparison of separate sediment samples from different parts of the same grab using pooled extraction replicates (sediment sample reproducibility), and C) comparison of all data from each grab (grab level reproducibility) (Fig. 1). Metabarcoding was done separately using total eukaryotic SSU $18 \mathrm{~S}$ rRNA V1-V2 region and metazoan cytochrome oxidase subunit I (COI) markers, to investigate the effects of spatial distance for the total eukaryotic community and for metazoans only. This 
125

126

127

128

129

130

131

132

133

134

135

136

137

138

139

140

141

142

143

144

145

146

147

148

149

150

151

152

153

154

155

156

157

158

159

160

161

162

163

164

sampling design was chosen in order to evaluate to which degree metabarcoding data from single and pooled DNA extracts were representative both of a particular sediment sample ("sediment sample level"), the grab of origin ("grab level"), and a the total multi-grab community dataset ("station level"). Results were evaluated using common alpha and beta diversity measures (richness, Shannon diversity, and Bray-Curtis pairwise dissimilarity). For the COI data, we also included existing macrofaunal biotic quality indices in the analysis.

The main aim of this study was to get a clearer picture of how eDNA sampling at different spatial scales impact perceived variation of organism distribution in metabarcoding data for marine sediment benthos at shelf depth, both for total eukaryotes and metazoans, to inform sampling design and intensity for further sediment eDNA studies in similar habitats.

\section{Materials \& Methods}

\section{Field sampling}

Sediment samples were collected using a $0.1 \mathrm{~m}^{2}$ van Veen grab during the 2018 environmental region II offshore monitoring campaign on the Norwegian Shelf, from three grab parallels at the monitoring station GK-DA-01 (58.5757 $\mathrm{N}, 1.6973^{\circ} \mathrm{E}, 116 \mathrm{~m}$ depth), here designated G1-G3. For each grab, five separate $50 \mathrm{~g}$ sediment samples (15 total) were collected from the top two $\mathrm{cm}$ of sediment, immediately frozen and kept at $-20^{\circ} \mathrm{C}$ until DNA extraction, here designated with Roman numerals I-V (Fig. 1A).

This station is part of the routine Norwegian offshore monitoring programme (Norwegian Environment Agency, 2020), and physiochemical parameter measurements and morphological species identification were also performed as part of the regular monitoring, which detected no faunal impact disturbance at this station (Hatlen et al. 2019). The sediment was classified as fine sand $(\varphi=3.03$, silt and clay $=11.14 \%$, sand $=83.13 \%$, gravel $=5.73 \%$, TOC $=0.48 \%)$.

\section{Lab processing}

Sediment samples were thawed at $+4^{\circ} \mathrm{C}$ and stirred by hand for approximately one minute prior to DNA extraction. Five $0.5 \mathrm{~g}$ sediment replicates, here designated with the letters A-E, were collected from each sediment sample (75 total) and extracted using a semi-automated protocol with Qiagen PowerSoil tubes and C1 solution, a Precellys homogenizer (3 x 6000 rpm for 40 s). After centrifugation (10K rpm for $1 \mathrm{~min}$ ) we used a Qiagen QIAsymphony SP robot (DSP DNA kit, Tissue LC protocol) for remaining extraction steps. Extract concentrations were measured using a Qubit 3.0 fluorometer (Thermo Fisher Scientific). Amplification and sequencing were performed on each individual extract from one sediment sample per grab $(n=3 * 5)$ and by pooling all five extracts from each sediment sample $(n=3 * 5)$ for a total of 30 sequencing results per marker (Fig. 1B). Average percent deviations of extract concentrations for each sediment sample were minor (2.65-6.17\%). Hence, we used equal volumes of each extract in extract pools. 
165

166

167

168

169

170

171

172

173

174

175

176

177

178

179

180

181

182

183

184

185

186

187

188

189

190

191

192

193

194

195

196

197

198

199

200

201

202

203

204

We used two markers for PCR amplification: the 18S rRNA gene V1-V2 region ( $350-400 \mathrm{bp})$ with primers SSU_F04mod (5'-GCTTGWCTCAAAGATTAAGCC-3') (Cordier pers. comm.) and SSU_R22 (5'-CCTGCTGCCTTCCTTRGA-3') (Sinniger et al. 2016), and the cytochrome oxidase subunit I (313 bp) with primers mlCOIintF-XT (5'-

GGWACWRGWTGRACWITITAYCCYCC-3') (Wangensteen et al. 2018) and jgHCO2198 (5'TAIACYTCIGGRTGICCRAARAAYCA-3') (Geller et al. 2013). PCR was performed using the KAPA3G Plant PCR kit (Kapa Biosystems) with adapter-linked primers including 12 random bases in order to improve variance during the first sequencing cycles. Annealing temperatures for $18 \mathrm{~S}$ and $\mathrm{COI}$ were $57^{\circ} \mathrm{C}$ and $45^{\circ} \mathrm{C}$ respectively. COI primer concentration was tripled relative to $18 \mathrm{~S}$ to account for the high number of primer ambiguous bases. Illumina dual index TruSeq i5/i7 barcodes were used for library preparation with equimolar PCR product concentration, and extraction and PCR negative controls were used to detect contamination during processing. Sequencing was performed on an Illumina MiSeq instrument using v3 with 300 bp chemistry at the Norwegian Sequencing Centre (University of Oslo, Norway). Demultiplexing was done by the sequencing center. Raw sequence data were uploaded to the NCBI Sequence Read Archive (SRA) as BioProject ID PRJNA704795, BioSample IDs SAMN18055833-41 and accession numbers SRR13781971-SRR13782030.

\section{Data processing and analysis}

Raw FASTQ files were quality checked using FastQC v0.11.8 (Andrews 2010), with further processing using a slightly modified version of the protocol from Lanzén et al. (2020). Briefly, vsearch v2.111.1 (Rognes et al. 2016) was used for read pair merging, filtering, singleton removal and chimera detection with maximum 20 and 40 mismatches allowed for $18 \mathrm{~S}$ and COI respectively. Primers were then trimmed with Cutadapt v1.18 (Martin, 2011) and reads with incomplete primer sequences or those outside the length range 330-450 bp (18S) or 274-330 bp (COI) were discarded. Clustering was done using SWARM v2.2.1 (Mahé et al. 2015) with default settings i.e. a maximum linkage difference (-d) of 1 and 3 for the fastidious step (-b), and post-clustering curation using LULU (Frøslev et al. 2017). Taxonomy was assigned using CREST (Lanzén et al. 2012) with the SilvaMod v128 database for $18 \mathrm{~S}$ and the BOLD (Ratnasingham \& Hebert 2007) database for COI, accessed February 2018 and adapted to CREST as part of release 3.2.1 (https://github.com/lanzen/CREST). Workflow scripts are available in the GitHub repository https://github.com/lanzen/Metamon1/

(vsearch_prep_18S_V1V2.sh, vsearch_prep_CO1XT.sh, SWARM_and_LULU_SSU.sh and SWARM_and_LULU_CO1.sh).

Potential contaminant OTUs were identified and removed based on both abundance profiles in the PCR and extraction blanks, using decontam (Davis et al. 2018), removing one 18S OTU but none from COI. Additional filtering in $\mathrm{R}$ included reducing cross-contamination by removing OTU occurrences at very low $(<1 \%)$ abundance compared to the average of all samples,

Peer) reviewing PDF | (2021:03:59310:1:0:NEW 15 May 2021) 
205

206

207

208

209

210

211

212

213

214

215

216

217

218

219

220

221

222

223

224

225

226

227

228

229

230

231

232

233

234

235

236

237

238

239

240

241

242

243

244

analogous to the UNCROSS algorithm (Edgar 2016). Further, OTUs below the minimum classification threshold or belonging to probable contaminant taxa (Insecta, Mammalia, Myxini, Arachnida, Actinopterygii, Collembola and Onychophorida) were removed. As we wanted to examine metazoan spatial distribution specifically, COI OTUs not classified to metazoan phylum rank or lower were removed. Finally, prior to alpha and beta diversity analysis, OTUs with an average relative abundance across samples corresponding to less than 3 copies in the sample with lowest sequencing depth $(0.003 \%$ for $18 \mathrm{~S} ; 0.1 \%$ for COI $)$ were also removed.

\section{Statistics}

Bray-Curtis pairwise dissimilarity values were calculated based on relative OTU abundances. Non-metric dimensional scaling (NMDS) was carried out using the R package vegan v3.2.1 (Oksanen et al. 2019; function metaMDS), as well as species accumulation curves. Pairwise dissimilarities were compared group-wise (between extracts, pooled intra-sample replicates and grab) using Wilcoxon rank sum tests.

For direct comparison with morphological values from the standard monitoring surveys in the area (Hatlen et al. 2019), Shannon diversity estimates were calculated using the base 2 rather than the natural logarithm. Shannon diversity values were calculated for both $18 \mathrm{~S}$ and COI data using the R BBI package (Cordier \& Pawlowski 2018). For COI, BBI was also used to calculate several macrofaunal biotic indices based on taxonomic classification of the macrofauna reads in the metazoan data, including the AZTI Marine Biotic Index (AMBI) (Borja et al. 2000), and the local Norwegian biotic indices NQI1 (Rygg 2006), ISI2012, and NSI2012 (Rygg \& Norling 2013), all using the BBI package. In order to compare the taxonomic coverage of the study $18 \mathrm{~S}$ and COI data with the Hatlen et al. (2019) morphological dataset from the same station, morphological species data were downloaded from the MOD database (DNV GL, 2021). The Euler diagrams were made using the R eulerr package (Larson, 2020). The R scripts used for all analyses are available in the repository https://github.com/lanzen/Metamon (WP2/R/Intra_plate_heterogeneity_18S.R and WP2/R/Intra_plate_heterogeneity_COI.R).

\section{Results}

\section{Data overview}

In total, 30 samples were sequenced for each marker, sequentially identified here by grab number (ten samples each for G1-G3), sediment sample (I-V, comprising five pooled extracts each) and finally individual extracts from sediment sample I from each grab (A-E). (Supplementary Table $\mathrm{S} 1)$.

The total $18 \mathrm{~S}$ dataset comprised 4,526,427 reads of which 3,778,901 (84\%) remained after filtering representing 893,214 unique paired sequences, with 103,321-153,079 filtered reads remaining for individual samples $($ mean $=125,963 ; \sigma=15,287)$. After swarm clustering 6,371

Peer] reviewing PDF | (2021:03:59310:1:0:NEW 15 May 2021) 
245 unique OTUs remained (6358 after taxonomic filtering). The three most common 18S OTUs in

246 the total dataset were an unclassified stramenopile, a member of the polychaete order

247 Phyllodocida, and an unidentified fungus. Other common OTUs included a nematode from the

248 order Enoplida and cercozoan taxa belonging to Cryothecomonas, Ebria and the CCW10 clade.

249 Metazoan taxa displayed higher inter-sample variation: One Phyllodocida OTU dominated all

250 sediment sample I data from the first grab, but was not present in any other samples. Other

251 Phyllodocida and nematode OTUs were also intermittently present at moderate abundances in

252 other samples (Fig. 2).

253

254

The total COI dataset comprised 4,833,536 raw sequences of which 3,313,941 (69\%) remained

255

after filtering. Removing sequences not classified to metazoan phylum level or lower removed an

256

257

258 additional $76 \%$ of reads for a final dataset of 788,499 reads representing 683,012 unique paired sequences, with 3,380-111,487 reads for individual samples (mean $=26,283 ; \sigma=28,657)$. After swarm clustering, 19,870 OTUs remained, of which the majority were removed due to being non-specific reads from bacteria or non-metazoan eukaryotes, leaving 1,759.Here, an

260 unclassified polychaete, corresponding to the Order Phyllodocida designation in the 18S dataset,

261 was the most abundant OTU, due to an almost complete dominance of this OTU in sediment

262 sample I in grab 1. Other abundant OTUs included the polychaete species Paramphinome

263 jeffreysii, Nephtys hystricis and Glycinde nordmanni, as well as members of taxa from other phyla such as Gastropoda, the nematode Adenophorea, Hydrozoa, the amphipod Harpinia antennaria and a couple of nemertean taxa (Fig. 2).

266

At the metazoan phylum level, 21 metazoan phyla were found in both the 18S and COI data, 24

268

269 in $18 \mathrm{~S}$ only, and 17 in COI only. One phylum was found in the morphological dataset only.

270 Similar numbers at class level were 21,24, 17 and 1, and at order level, 16, 55, 45 and 8. This

271 information, together with the relative abundances of the $18 \mathrm{~S}, \mathrm{COI}$ and morphological datasets at phylum, class and order level, is given in Fig. S1.

272

\section{Variability between samples}

274 Bray-Curtis 18S pairwise dissimilarities were the lowest between individual extracts from the 275 same sample (median=0.24), significantly higher between pooled extracts from different samples 276 within the same grab (median=0.39, $\mathrm{p}<1 \mathrm{E}-5$ ), and higher still between pooled extracts from 277 different grabs (median=0.43, $\mathrm{p}=0.02$ ) (Fig. 3A). The NMDS plot showed clustering according 278 to grab identity, though grab 1 appeared more heterogeneous than grabs 2 and 3 . In addition to 279 the Phyllodocida-dominated grab 1 outlier, comprising all sediment sample I extracts, different 280 grab 1 sediment samples were also less similar to each other than corresponding samples from 281 grabs 2 and 3 were (Fig. 3B), which appeared to be caused mainly by differences in abundances 282 of major metazoans (Fig. 2A).

283 
284 Bray-Curtis COI pairwise dissimilarities were substantially higher than their $18 \mathrm{~S}$ equivalents. As 285 expected, individual extracts from the same sediment sample had the lowest dissimilarities 286 (median=0.49) while those from pooled extracts from different samples in the same grab were 287 significantly higher (median=0.89, $\mathrm{p}<1 \mathrm{E}-12$ ), consistent with $18 \mathrm{~S}$ data. In contrast to $18 \mathrm{~S}$

288 however, pooled extracts from samples from different grabs were not more dissimilar than those 289 from the same grab (median=0.92) (Fig. 3C). Corresponding to the $18 \mathrm{~S}$ results, the COI NMDS 290 analysis showed that grab 1, sediment sample I datapoints were outliers in the dataset. For the 291 remaining samples, grab level clustering could not be readily discerned (Fig. 3D).

292

293

294

295

296

297

298

299

300

301

302

303

304

305

306

307

308

309

310

311

312

313

314

315

316

317

318

319

320

321

322

323

\section{OTU coverage}

For the entire 18S dataset, 1030 OTUs remained after abundance filtering, comprising all three grabs (see Supplementary Table S1 for a full overview). The number of OTUs for each of the three grabs ranged from 933-959 (Table 1), with 845 OTUs shared between all grabs, 105 OTUs in two grabs, and 80 in a single grab only (Fig. 4A). For the five individual sediment samples of each of the three grabs, represented by five pooled extraction replicates each $(n=15)$, abundance filtered OTUs ranged from $622-812$ (60-79\% of total). Single extracts from the three sediment samples were also sequenced separately (one sample from each grab, $n=15$ ) and their OTU richness ranged from $641-706$ (62-69\% of total) (Table 1).

Species accumulation curves for abundance filtered $18 \mathrm{~S}$ data exhibited an initial steep increase in richness going from one to two samples both when accumulating individual extracts from the same sediment and when accumulating pooled extracts from different sediment samples from the same grab. The slope decrease was slightly less clear at the grab level, indicating higher heterogeneity here compared to individual extracts from the same sediment sample (Fig. 5).

For the entire COI dataset at metazoan phylum level or below, 108 OTUs were retained after abundance filtering, comprising all three grabs (see Supplementary Table S1 for a full overview). The abundance filtered OTU richness per grab was $83-87$ (77-81\% of total) (Table 1), with 63 OTUs shared between all grabs, 20 OTUs in two grabs, and 25 in a single grab only (Fig. 4B). For individual sediment samples ( $\mathrm{n}=15$, made from pools of five extracts each), richness ranged from $37-67$ (34-62\% of total), while single extract richness from (five from one sub-sample from each grab, $n=15$ ) ranged from $35-59$ (32-55\% of total) (Table 1).

As seen in the species accumulation curves, COI spatial replicates caused a larger relative increase than in the $18 \mathrm{~S}$ data, indicating lower sampling coverage for metazoan COI data compared to the eukaryote $18 \mathrm{~S}$ data (Fig. 5).

\section{Diversity and sensitivity index values}

Shannon values were higher and more consistent for pooled samples relative to single extract samples, and for $18 \mathrm{~S}$ compared to COI, while COI biotic index values were more consistent 
324 between samples than corresponding COI Shannon values. The range of Shannon values for $18 \mathrm{~S}$

325

326

327

328

329

330

331

332

333

334

335

336

337

338

339

340

341

342

343

344

345

346

347

348

349

350

351

352

353

354

355

356

357

358

359

360

361

362

363

and COI, as well as biotic index values for COI, are given in Table 2. Individual values for each sample can also be found in Supplementary Table 1.

\section{Discussion}

18S total eukaryote richness was surprisingly well represented at pooled extract and grab level:

Of the total multi-grab $18 \mathrm{~S}$ dataset, more than $90 \%$ of OTUs could be recovered from the sum of pooled samples from each of the single grabs. More practically relevant is that even for the single five pooled extract sediment samples, a median $69-75 \%$ of the total abundance filtered $18 \mathrm{~S}$ OTUs were recovered. Furthermore, even a modest increase in sampling effort substantially increased sampling coverage when combining sediment from different parts of the same grab or different grabs. Thus obtaining representative coverage of the total eukaryote community was feasible with a reasonable amount of sampling effort.

While the Shannon index and other alpha diversity estimates should not be uncritically used with molecular data, considering that relative abundance can be heavily affected by primer bias and data treatment (e.g. Krehenwinkel et al. 2017), it is still useful to analyze the consistency of obtained Shannon diversity values. The values obtained using $18 \mathrm{~S}$ (median=6.25) were somewhat higher than those obtained using morphological identification of macroinvertebrates from samples collected concurrently (median $=5.48$; Hatlen et al. 2019). Further, 18S Shannon median values were slightly higher for pooled extracts, representing $2.5 \mathrm{~g}$ of sediment, than single $0.5 \mathrm{~g}$ extracts. The positive influence of increased sediment volume on sample diversity is well established (e.g. Nascimento et al. 2018), and kits such as the Qiagen DNeasy PowerMax Soil Kit or the Soil DNA Isolation Maxi Kit can be used to increase sample sediment volume as an alternative to the use of extract replicates as used here and in e.g. Lanzén et al. (2017).

The 18S pairwise sample dissimilarities were lowest in the intra-sediment samples, followed by sediment samples from the same grab, and finally highest for samples from different grabs, with the exception that COI based dissimilarities were not significantly higher between grabs than different sediment samples within the same grab. Thus we could discern several levels of spatial heterogeneity in our data, meaning that both sampling from different points within a grab and including samples from separate grabs increased community coverage at station level relative to concentrated sampling. Making sample replicates from within the same grab (or alternatively box or multi corer) is not only easier, but our results show that it contributed almost as much to improving the situation as replicating grabs did. However, even for the $18 \mathrm{~S}$ data, the heterogeneous metazoan distribution in one of our grab replicates shows how entire outlier grabs can substantially and randomly influence perceived sample variability when employing markers that capture metazoans in addition to single-celled eukaryotes. Thus, spatial replication is ideally needed even at grab level. Alternatively, another viable strategy for reducing spatial heterogeneity is to employ eukaryote markers that minimize the metazoan complement. In their

Peer) reviewing PDF | (2021:03:59310:1:0:NEW 15 May 2021) 
364

365

366

367

368

369

370

371

372

373

374

375

376

377

378

379

380

381

382

383

384

385

386

387

388

389

390

391

392

393

394

395

396

397

398

399

400

401

402

403

work on Mediterranean deep-sea sediment, Guardiola at al. (2015) compared both 18S V7 data between multi corer mini core replicates, and between replicate box corers from the same station. Compared to the same and separate grab replicate mean dissimilarities here of 0.39 and 0.43 using $18 \mathrm{~S} \mathrm{V1-V2} \mathrm{(but} \mathrm{both} \mathrm{around} 0.9$ for metazoans for COI), Guardiola et al. reported higher mean Bray-Curtis dissimilarities of around 0.6 and 0.7 respectively, though differences in source habitat, sample design and processing to this study make direct comparison difficult. Finally, several studies have sequenced prokaryote communities (e.g. Aylagas et al. 2017; Lanzén et al. 2020), though we are not aware of any study where prokaryote heterogeneity in marine sediments is examined at the spatial scapes examined here.

In contrast to $18 \mathrm{~S}, \mathrm{COI}$ metabarcoding data from sediment eDNA typically contains a high number of prokaryote and unassignable eukaryote reads, as observed here and previously by e.g. Collins et al. (2019) and Mauffrey et al. (2020). We note that removing non-target reads to focus on metazoans assigned at phylum rank or lower exclusively drastically reduced total read depth to a very variable extent in different samples, leaving 3-67\% of total reads for further analysis; a consistent challenge for COI that is difficult to avoid without concentrating metazoan DNA through using community (e.g. bulk) samples rather than sediment. Heterogeneity in the COI dataset was much higher than in corresponding $18 \mathrm{~S}$ samples, and dissimilarities between different sediment samples from the same grab were not significantly lower than between grabs. Though around half of total COI OTUs could typically be found in individual sediment samples, coverage was consistently lower than $18 \mathrm{~S}$ for all levels of sampling. While the reduction in read depth due to non-target reads probably plays a role here, these findings also support the conclusion from e.g. Lanzén et al. (2017) that multicellular metazoans have a more heterogeneous distribution than single-celled eukaryotes at the scale examined here.

A common argument for including metazoans in eDNA impact monitoring studies is the ability to use existing macrofauna-based biotic indices such as AMBI, or local variants such as the Norwegian ISI2012, NSI2012 and NQI1 indices. The standard monitoring survey found no disturbed fauna at this station based on alpha diversity, biotic index values and an overall qualitative assessment of the morphological species data (Hatlen et al. 2019). Applying the same biotic indices to identifiable macrofauna in our COI data generated results that were mostly consistent with this observation ("no disturbed fauna"): The obtained gAMBI values (median 1.68 ) would classify the corresponding sample as "unpolluted" (0.0-1.2, dominate by ecogroup I) or as "slightly polluted" (1.2-3.3, dominated by ecogroup II/III) (Borja et al. 2000). Calculated on presence-absence data only, (pa)gAMBI values indicated a slightly better status with less variation across all samples, classifying all but one sample as "unpolluted". Though originally developed for Norwegian coastal sediments, and thus not completely representative of an offshore locality such as the station studied here, the most consistent biotic index values were observed for the indices ISI2012 and NSI2012, where all samples, according to the Norwegian implementation of the Water Directive, corresponded to "very good" or "good" environmental 
404 status (Direktoratsguppen vanndirektivet 2018). The compound NQI index, incorporating AMBI 405 (Rygg 2006), was less consistent (corresponding to "very good" to "moderate"). As a whole, 406 COI-derived biotic index values were comparable to classification of biotic index results from 407 the morphological species data ("good" to "very good") (Hatlen et al. 2019).

408

409

While there was still considerable variation between samples, macrofaunal index values were thus more consistent than other COI diversity metrics, possibly because they are calculated from a limited list of taxa with assigned sensitivity status that presumably are represented among the more abundant OTUs in the molecular dataset. Out of the 105 COI OTUs, 71 were represented in at least one biotic index and could be used to calculate quality values, which corresponds well to the relatively good specific reference database coverage of this region (Hestetun et al. 2020). Thus our results show that despite the increased noise of the metazoan COI data compared to $18 \mathrm{~S}$ here, the ability to use existing biotic indices on COI molecular data, as done in previous studies (Aylagas et al. 2018; Lejzerowicz et al. 2015), can still make COI metabarcoding a useful tool in environmental quality assessment and compliance with current standards.

\section{Conclusions}

In summary our results show that, given the small amount of source sediment used, total eukaryotic diversity was well represented with a manageable number of biological replicates, demonstrating the ability of metabarcoding to consistently detect a eukaryotic core community. However, there was a consistent pattern of increasing heterogeneity with increased spatial distance, and individual extracts and grab sediment samples were vulnerable to large read abundances of single metazoan OTUs. Thus extract and biological replicates both from different areas within the same grab and from grab replicates are suggested to both dilute the effect of single dominating OTUs and maximize coverage of the biological community. The inconsistent COI results highlight the challenges in using a metazoan approach for direct sediment extraction, both in terms of non-target sequences and inter-replicate heterogeneity. However, COI biotic index values proved more stable than direct alpha- and beta diversity metrics, adding to the potential value of this marker for environmental monitoring in the context of current monitoring standards.

\section{Acknowledgements}

We would like to thank Jessica Louise Ray and Aud Larsen for valuable input on study design and analysis. We would also like to thank Anita Skaarstad and Ane Kjølhamar from Equinor AS and Grethe Kjeilen-Eilertsen and Thomas Merzi from Total for project input and support.

Finally, we would like to thank Kristin Hatlen and Frøydis Lygre at Stim Miljøtjenester AS for collecting the sediment samples during the 2018 North Sea region II monitoring campaign. 
442 References

443 Alberdi A, Aizpurua O, Gilbert MTP, and Bohmann K. 2018. Scrutinizing key steps for reliable

444 metabarcoding of environmental samples. Methods in Ecology and Evolution 9:134-147.

$445 \quad 10.1111 / 2041-210 x .12849$

446 Andrews S. 2010. FastQC: A Quality Control Tool for High Throughput Sequence Data.

$447 \quad$ v0.11.8 ed. Available online at:

$448 \quad$ http://www.bioinformatics.babraham.ac.uk/projects/fastqc/.

449

450

451

452

453

454

455

456

457

458

459

460

461

462

463

464

465

466

467

468

469

470

471

472

473

474

475

476

477

478

479

480

481

Andújar C, Arribas P, Yu DW, Vogler AP, and Emerson BC. 2018. Why the COI barcode should be the community DNA metabarcode for the metazoa. Molecular Ecology 27:3968-3975. $10.1111 / \mathrm{mec} .14844$

Atherton S, and Jondelius U. 2020. Biodiversity between sand grains: Meiofauna composition across southern and western Sweden assessed by metabarcoding. Biodiversity Data Journal 8. 10.3897/BDJ.8.e51813

Atienza S, Guardiola M, Præbel K, Antich A, Turon X, and Wangensteen O. 2020. DNA Metabarcoding of Deep-Sea Sediment Communities Using COI: Community Assessment, Spatio-Temporal Patterns and Comparison with 18S rDNA. Diversity 12. https://doi.org/10.3390/d12040123

Aylagas E, Borja Á, Irigoien X, and Rodríguez-Ezpeleta N. 2016. Benchmarking DNA Metabarcoding for Biodiversity-Based Monitoring and Assessment. Frontiers in Marine Science 3. 10.3389/fmars.2016.00096

Aylagas E, Borja Á, Tangherlini M, Dell'Anno A, Corinaldesi C, Michell CT, Irigoien X, Danovaro R, and Rodríguez-Ezpeleta N. 2017. A bacterial community-based index to assess the ecological status of estuarine and coastal environments. Marine Pollution Bulletin 114:679-688. https://doi.org/10.1016/j.marpolbul.2016.10.050

Aylagas E, Borja Á, Muxika I, and Rodríguez-Ezpeleta N. 2018. Adapting metabarcoding-based benthic biomonitoring into routine marine ecological status assessment networks.

Ecological Indicators 95:194-202. https://doi.org/10.1016/j.ecolind.2018.07.044

Baird DJ, and Hajibabaei M. 2012. Biomonitoring 2.0: a new paradigm in ecosystem assessment made possible by next-generation DNA sequencing. Molecular Ecology 21:2039-2044. 10.1111/j.1365-294X.2012.05519.x

Borja A, Franco J, and Pérez V. 2000. A Marine Biotic Index to Establish the Ecological Quality of Soft-Bottom Benthos Within European Estuarine and Coastal Environments. Marine Pollution Bulletin 40:1100-1114. https://doi.org/10.1016/S0025-326X(00)00061-8

Brannock PM, and Halanych KM. 2015. Meiofaunal community analysis by high-throughput sequencing: Comparison of extraction, quality filtering, and clustering methods. Marine Genomics 23:67-75. https://doi.org/10.1016/j.margen.2015.05.007

Collins RA, Bakker J, Wangensteen OS, Soto AZ, Corrigan L, Sims DW, Genner MJ, and Mariani S. 2019. Non-specific amplification compromises environmental DNA metabarcoding with COI. Methods in Ecology and Evolution 10:1985-2001. 10.1111/2041-210x.13276 
482 Cordier T, and Pawlowski J. 2018. BBI: an R package for the computation of Benthic Biotic $483 \quad$ Indices from composition data. Metabarcoding and Metagenomics 2:e25649.

484 Cristescu ME, and Hebert PDN. 2018. Uses and Misuses of Environmental DNA in Biodiversity 485 Science and Conservation. Annual Review of Ecology, Evolution, and Systematics 49:209230. 10.1146/annurev-ecolsys-110617-062306

488

489

490

491

492

493

494

495

496

497

498

499

500

501

502

503

504

505

506

507

508

509

510

511

512

513

514

515

516

517

518

519

520

Davis NM, Proctor D, Holmes SP, Relman DA, Callahan BJ (2018) Simple statistical identification and removal of contaminant sequences in marker-gene and metagenomics data, Microbiome 6, 226.

DiBattista JD, Reimer JD, Stat M, Masucci GD, Biondi P, De Brauwer M, Wilkinson SP, Chariton AA, and Bunce M. 2020. Environmental DNA can act as a biodiversity barometer of anthropogenic pressures in coastal ecosystems. Scientific Reports 10:8365. 10.1038/s41598-020-64858-9

Dickie IA, Boyer S, Buckley HL, Duncan RP, Gardner PP, Hogg ID, Holdaway RJ, Lear G, Makiola A, Morales SE, Powel JR and Weaver L. 2018. Towards robust and repeatable sampling methods in eDNA-based studies. Molecular Ecology Resources, 18(5): 940-952.

Direktoratsguppen vanndirektivet. 2018. Veileder 02:2018. Klassifisering av miljøtilstand i vann. p 222.

Djurhuus A, Port J, Closek CJ, Yamahara KM, Romero-Maraccini O, Walz KR, Goldsmith DB, Michisaki R, Breitbart M, Boehm AB, and Chavez FP. 2017. Evaluation of Filtration and DNA Extraction Methods for Environmental DNA Biodiversity Assessments across Multiple Trophic Levels. Frontiers in Marine Science 4:314.

DNV GL. (2021). The Environmental Monitoring Database MOD. Available from DNV GL. Retrieved 2020-11-30. https://projects.dnv.com/MOD/MODKart/

Edgar RC. 2016. UNCROSS: Filtering of high-frequency cross-talk in 16S amplicon reads. bioRxiv:088666. 10.1101/088666

Elbrecht V, and Leese F. 2015. Can DNA-Based Ecosystem Assessments Quantify Species Abundance? Testing Primer Bias and Biomass--Sequence Relationships with an Innovative Metabarcoding Protocol. PLOS ONE 10:e0130324-e0130324.

10.1371/journal.pone.0130324

Faria LCd, Di Domenico M, Andrade SCS, Santos MCd, Fonseca G, Zanol J, and Amaral ACZ. 2018. The use of metabarcoding for meiofauna ecological patterns assessment. Marine Environmental Research 140:160-168. https://doi.org/10.1016/j.marenvres.2018.06.013

Fonseca VG, Carvalho GR, Sung W, Johnson HF, Power DM, Neill SP, Packer M, Blaxter ML, Lambshead PJD, Thomas WK, and Creer S. 2010. Second-generation environmental sequencing unmasks marine metazoan biodiversity. Nature Communications 1:98. 10.1038/ncomms 1095

Frøslev TG, Kjøller R, Bruun HH, Ejrnæs R, Brunbjerg AK, Pietroni C, and Hansen AJ. 2017. Algorithm for post-clustering curation of DNA amplicon data yields reliable biodiversity estimates. Nature Communications 8:1188. 10.1038/s41467-017-01312-x

Peer) reviewing PDF | (2021:03:59310:1:0:NEW 15 May 2021) 
521 Geller J, Meyer C, Parker M, and Hawk H. 2013. Redesign of PCR primers for mitochondrial

522

523

524

525

526

527

528

529

530

531

532

533

534

535

536

537

538

539

540

541

542

543

544

545

546

547

548

549

550

551

552

553

554

555

556

557

558

559

560 cytochrome c oxidase subunit I for marine invertebrates and application in all-taxa biotic surveys. Molecular Ecology Resources 13:851-861. 10.1111/1755-0998.12138

Guardiola M, Uriz MJ, Taberlet P, Coissac E, Wangensteen OS, and Turon X. 2015. Deep-Sea, Deep-Sequencing: Metabarcoding Extracellular DNA from Sediments of Marine Canyons. PLOS ONE 10.

Guardiola M, Wangensteen OS, Taberlet P, Coissac E, Uriz MJ, and Turon X. 2016. Spatiotemporal monitoring of deep-sea communities using metabarcoding of sediment DNA and RNA. PeerJ 4:e2807. 10.7717/peerj.2807

Hatlen K, Kvalø SE, Torvanger R, Hadler-Jacobsen S, Alme Ø, and Johansen P-O. 2019. Miljøovervåking av olje- og gassfelt i Region II, 2018 - Hovedrapport. STIM Miljø Rapport. p 378.

Hestetun JT, Bye-Ingebrigtsen E, Nilsson RH, Glover AG, Johansen PO, and Dahlgren TG. 2020. Significant taxon sampling gaps in DNA databases limit the operational use of marine macrofauna metabarcoding. Marine Biodiversity 50(5):1-9.

He X, Sutherland TF, and Abbott CL. 2021. Improved efficiency in eDNA metabarcoding of benthic metazoans by sieving sediments prior to DNA extraction. Environmental DNA n/a. https://doi.org/10.1002/edn3.172

ISO. 2014. ISO 16665:2014. Water quality — Guidelines for quantitative sampling and sample processing of marine soft-bottom macrofauna. International Organization for Standardization. p 33.

Larsson J. 2020. eulerr: Area-Proportional Euler and Venn Diagrams with Ellipses. Version 6.1.0 [R package / software]. Available from: http://CRAN.R-project.org/package=eulerr.

Keeley N, Wood SA, and Pochon X. 2018. Development and preliminary validation of a multitrophic metabarcoding biotic index for monitoring benthic organic enrichment. Ecological Indicators 85:1044-1057. https://doi.org/10.1016/j.ecolind.2017.11.014

Kelly RP, Shelton AO, and Gallego R. 2019. Understanding PCR Processes to Draw Meaningful Conclusions from Environmental DNA Studies. Scientific Reports 9:12133. 10.1038/s41598-019-48546-x

Krehenwinkel H, Wolf M, Lim JY, Rominger AJ, Simison WB, and Gillespie RG. 2017. Estimating and mitigating amplification bias in qualitative and quantitative arthropod metabarcoding. Scientific reports, 7:1-12.

Lanzén A, Jørgensen SL, Huson DH, Gorfer M, Grindhaug SH, Jonassen I, Øvreås L, and Urich T. 2012. CREST--classification resources for environmental sequence tags. PLOS ONE 7:e49334-e49334. 10.1371/journal.pone.0049334

Lanzén A, Lekang K, Jonassen I, Thompson EM, and Troedsson C. 2016. High-throughput metabarcoding of eukaryotic diversity for environmental monitoring of offshore oil-drilling activities. Molecular Ecology 25:4392-4406. 10.1111/mec.13761

Lanzén A, Lekang K, Jonassen I, Thompson EM, and Troedsson C. 2017. DNA extraction replicates improve diversity and compositional dissimilarity in metabarcoding of 
561

562

563

564

565

566

567

568

569

570

571

572

573

574

575

576

577

578

579

580

581

582

583

584

585

586

587

588

589

590

591

592

593

594

595

596

597

598

599

eukaryotes in marine sediments. PLOS ONE 12:e0179443-e0179443.

10.1371/journal.pone.0179443

Lanzén A, Mendibil I, Borja Á, and Alonso-Sáez L. 2020. A microbial mandala for environmental monitoring: Predicting multiple impacts on estuarine prokaryote communities of the Bay of Biscay. Molecular Ecology n/a. 10.1111/mec.15489

Laroche O, Kersten O, Smith CR, and Goetze E. 2020. Environmental DNA surveys detect distinct metazoan communities across abyssal plains and seamounts in the western Clarion Clipperton Zone. Molecular Ecology n/a. 10.1111/mec.15484

Leasi F, Sevigny JL, Laflamme EM, Artois T, Curini-Galletti M, de Jesus Navarrete A, Di Domenico M, Goetz F, Hall JA, Hochberg R, Jörger KM, Jondelius U, Todaro MA, Wirshing HH, Norenburg JL, and Thomas WK. 2018. Biodiversity estimates and ecological interpretations of meiofaunal communities are biased by the taxonomic approach. Communications Biology 1:112. 10.1038/s42003-018-0119-2

Lejzerowicz F, Esling P, Pillet L, Wilding TA, Black KD, and Pawlowski J. 2015. Highthroughput sequencing and morphology perform equally well for benthic monitoring of marine ecosystems. Scientific Reports 5:13932. 10.1038/srep13932

Lekang K, Thompson EM, and Troedsson C. 2015. A comparison of DNA extraction methods for biodiversity studies of eukaryotes in marine sediments. Aquatic Microbial Ecology $75: 15-25$.

Leray M, and Knowlton N. 2017. Random sampling causes the low reproducibility of rare eukaryotic OTUs in Illumina COI metabarcoding. PeerJ 5:e3006. 10.7717/peerj.3006

Macher J-N, Vivancos A, Piggott JJ, Centeno FC, Matthaei CD, and Leese F. 2018. Comparison of environmental DNA and bulk-sample metabarcoding using highly degenerate cytochrome c oxidase I primers. Molecular Ecology Resources 18:1456-1468. 10.1111/1755-0998.12940

Mahé F, Rognes T, Quince C, de Vargas C, and Dunthorn M. 2015. Swarm v2: highly-scalable and high-resolution amplicon clustering. PeerJ 3:e1420-e1420. 10.7717/peerj.1420

Mauffrey F, Cordier T, Apothéloz-Perret-Gentil L, Cermakova K, Merzi T, Delefosse M, Blanc P, and Pawlowski J. 2020. Benthic monitoring of oil and gas offshore platforms in the North Sea using environmental DNA metabarcoding. Molecular Ecology n/a. $10.1111 / \mathrm{mec} .15698$

Nascimento FJA, Lallias D, Bik HM, and Creer S. 2018. Sample size effects on the assessment of eukaryotic diversity and community structure in aquatic sediments using highthroughput sequencing. Scientific Reports 8:11737. 10.1038/s41598-018-30179-1

NS. 2009. NS 9415:2009. Marine fish farms - Requirements for site survey, risk analyses, design, dimensioning, production, installation and operation Norwegian Standard. p 101.

Norwegian Environment Agency. 2020. M-408. Guidelines for environmental monitoring of petroleum activities on the Norwegian continental shelf, 2020 revision.: Norwegian Environment Agency. p 68. 
600 Nøland SA, Tvete H, Brooks L, Fjukmoen Ø, Volan C, Karlsen H, Melsom F, and Ulfsnes A.

601

602

603

604

605

606

607

608

609

610

611

612

613

614

615

616

617

618

619

620

621

622

623

624

625

626

627

628

629

630

631

632

633

634

635

636

637

638

639

2013. Miljøovervåking og grunnlagsundersøkelser i Region II 2012. DNV Rapport. p 319.

Oksanen J, Blanchet FG, Friendly M, Kindt R, Legendre P, McGlinn D, Minchin PR, O'Hara RB, Simpson GL, Solymos P, Stevens MHH, Szoecs E, and Wagner H. 2019. vegan: Community Ecology Package. Version 2.5-6 [R package / software]. 2.5-6 ed. Available from: http://CRAN.R-project.org/package=vegan.

Pearman JK, Keeley NB, Wood SA, Laroche O, Zaiko A, Thomson-Laing G, Biessy L, Atalah J, and Pochon X. 2020. Comparing sediment DNA extraction methods for assessing organic enrichment associated with marine aquaculture. PeerJ 8:e10231. 10.7717/peerj.10231

Penton CR, Gupta VVSR, Yu J, and Tiedje JM. 2016. Size Matters: Assessing Optimum Soil Sample Size for Fungal and Bacterial Community Structure Analyses Using High Throughput Sequencing of rRNA Gene Amplicons. Frontiers in Microbiology 7. 10.3389/fmicb.2016.00824

Piñol J, Senar MA, and Symondson WOC. 2019. The choice of universal primers and the characteristics of the species mixture determine when DNA metabarcoding can be quantitative. Molecular Ecology 28:407-419. 10.1111/mec.14776

Ratnasingham S, and Hebert PDN. 2007. bold: The Barcode of Life Data System (http://www.barcodinglife.org). Molecular ecology notes 7:355-364. 10.1111/j.14718286.2007.01678.x

Rognes T, Flouri T, Nichols B, Quince C, and Mahé F. 2016. VSEARCH: a versatile open source tool for metagenomics. PeerJ 4:e2584. 10.7717/peerj.2584

Roussel, J. M., Paillisson, J. M., Treguier, A., \& Petit, E. (2015). The downside of eDNA as a survey tool in water bodies. Journal of Applied Ecology, 52(4), 823-826. 10.1111/13652664.12428

Rygg B. 2006. NIVA 6475-2013. Developing indices for quality-status classification of marine soft-bottom fauna in Norway. NIVA Report: Norwegian Institute for Water Research. p 38.

Rygg B, and Norling K. 2013. NIVA 6475-2013. Norwegian Sensitivity Index (NSI) for marine macroinvertebrates, and an update of Indicator Species Index (ISI). NIVA Report: Norwegian Institute for Water Research. p 47.

Schander C, and Willassen E. 2005. What can biological barcoding do for marine biology? Marine Biology Research 1:79-83. 10.1080/17451000510018962

Sinniger F, Pawlowski J, Harii S, Gooday AJ, Yamamoto H, Chevaldonné P, Cedhagen T, Carvalho G, and Creer S. 2016. Worldwide Analysis of Sedimentary DNA Reveals Major Gaps in Taxonomic Knowledge of Deep-Sea Benthos. Frontiers in Marine Science 3. 10.3389/fmars.2016.00092

Smith DP, and Peay KG. 2014. Sequence Depth, Not PCR Replication, Improves Ecological Inference from Next Generation DNA Sequencing. PLOS ONE 9:e90234. 10.1371/journal.pone.0090234

Stoeck T, Kochems R, Forster D, Lejzerowicz F, and Pawlowski J. 2018. Metabarcoding of benthic ciliate communities shows high potential for environmental monitoring in salmon

Peer] reviewing PDF | (2021:03:59310:1:0:NEW 15 May 2021) 
640 aquaculture. Ecological Indicators 85:153-164.

$641 \quad$ https://doi.org/10.1016/j.ecolind.2017.10.041

642 Tang CQ, Leasi F, Obertegger U, Kieneke A, Barraclough TG, and Fontaneto D. 2012. The

643 widely used small subunit $18 \mathrm{~S}$ rDNA molecule greatly underestimates true diversity in

644 biodiversity surveys of the meiofauna. Proceedings of the National Academy of Sciences

$645 \quad$ 109:16208-16212. 10.1073/pnas.1209160109

646 Wangensteen OS, Palacín C, Guardiola M, and Turon X. 2018. DNA metabarcoding of littoral

647 hard-bottom communities: high diversity and database gaps revealed by two molecular

648 markers. PeerJ 6:e4705. 10.7717/peerj.4705

649 Weigand AM, and Macher J-N. 2018. A DNA metabarcoding protocol for hyporheic freshwater

650 meiofauna: Evaluating highly degenerate COI primers and replication strategy.

651 Metabarcoding and Metagenomics 2. 10.3897/mbmg.2.26869

652 Zhou J, Wu L, Deng Y, Zhi X, Jiang Y-H, Tu Q, Xie J, Van Nostrand JD, He Z, and Yang Y.

653 2011. Reproducibility and quantitation of amplicon sequencing-based detection. The ISME

654 Journal 5:1303-1313. 10.1038/ismej.2011.11

655 Zinger L, Bonin A, Alsos IG, Bálint M, Bik H, Boyer F, Chariton AA, Creer S, Coissac E,

656 Deagle BE, De Barba M, Dickie IA, Dumbrell AJ, Ficetola GF, Fierer N, Fumagalli L,

657 Gilbert MTP, Jarman S, Jumpponen A, Kauserud H, Orlando L, Pansu J, Pawlowski J,

658 Tedersoo L, Thomsen PF, Willerslev E, and Taberlet P. 2019. DNA metabarcoding-Need

659 for robust experimental designs to draw sound ecological conclusions. Molecular Ecology

$660 \quad 28: 1857-1862.10 .1111 /$ mec. 15060 


\section{Table $\mathbf{1}$ (on next page)}

Abundance filtered OTU richness at grab, sediment samples and individual extract level.

Information is given as absolute numbers and percentage of total dataset for the $18 \mathrm{~S}$ rDNA and COI datasets. Whole grab values are based on sum of pooled extract OTUs, excluding individual same-sediment sample extracts. 
1 Table 1. Abundance filtered OTU richness at grab, sediment samples and individual extract 2 level. Information is given as absolute numbers and percentage of total dataset for the 18S rDNA 3 and COI datasets. Whole grab values are based on sum of pooled extract OTUs, excluding

4 individual same-sediment sample extracts.

\begin{tabular}{|c|c|c|c|c|c|c|c|c|}
\hline \multicolumn{9}{|c|}{$\underline{18 S}$ absolute counts } \\
\hline & \multicolumn{3}{|c|}{ Single extracts } & \multicolumn{3}{|c|}{ Intra-grab, 5 pooled extracts } & \multirow{2}{*}{\multicolumn{2}{|c|}{$\begin{array}{l}\text { Whole grab } \\
\text { Value }\end{array}$}} \\
\hline & Min & Max & Median & Min & $\operatorname{Max}$ & Median & & \\
\hline Grab 1 & 641 & 666 & 659 & 622 & 812 & 752 & & 959 \\
\hline Grab 2 & 642 & 656 & 646 & 711 & 782 & 775 & & 933 \\
\hline Grab 3 & 666 & 706 & 679 & 695 & 779 & 711 & & 933 \\
\hline \multicolumn{9}{|c|}{$18 S$ percentage of total $(n=1030)$} \\
\hline & \multicolumn{3}{|c|}{ Single extracts } & \multicolumn{3}{|c|}{ Intra-grab, 5 pooled extracts } & \multirow{2}{*}{\multicolumn{2}{|c|}{$\begin{array}{l}\text { Whole grab } \\
\text { Value }\end{array}$}} \\
\hline & Min & Max & Median & Min & Max & Median & & \\
\hline Grab 1 & $62 \%$ & $65 \%$ & $64 \%$ & $60 \%$ & $79 \%$ & $73 \%$ & & $93 \%$ \\
\hline Grab 2 & $62 \%$ & $64 \%$ & $63 \%$ & $69 \%$ & $76 \%$ & $75 \%$ & & $91 \%$ \\
\hline Grab 3 & $65 \%$ & $69 \%$ & $66 \%$ & $67 \%$ & $76 \%$ & $69 \%$ & & $91 \%$ \\
\hline \multicolumn{9}{|c|}{ COI absolute counts } \\
\hline & \multicolumn{3}{|c|}{ Single extracts } & \multicolumn{3}{|c|}{ Intra-grab, 5 pooled extracts } & \multirow{2}{*}{\multicolumn{2}{|c|}{$\begin{array}{l}\text { Whole grab } \\
\text { Value }\end{array}$}} \\
\hline & Min & Max & Median & Min & Max & Median & & \\
\hline Grab 1 & 35 & 48 & 39 & 37 & 63 & 60 & & 83 \\
\hline Grab 2 & 45 & 55 & 49 & 47 & 67 & 48 & & 84 \\
\hline Grab 3 & 52 & 59 & 56 & 38 & 59 & 51 & & 87 \\
\hline \multicolumn{9}{|c|}{ COI percentage of total $(n=108)$} \\
\hline & \multicolumn{3}{|c|}{ Single extracts } & \multicolumn{3}{|c|}{ Intra-grab, 5 pooled extracts } & Whole grab & \\
\hline & Min & Max & Median & Min & Max & Median & Value & \\
\hline Grab 1 & $32 \%$ & $44 \%$ & $36 \%$ & $34 \%$ & $58 \%$ & $56 \%$ & & $77 \%$ \\
\hline Grab 2 & $42 \%$ & $51 \%$ & $45 \%$ & $44 \%$ & $62 \%$ & $44 \%$ & & $78 \%$ \\
\hline Grab 3 & $48 \%$ & $55 \%$ & $52 \%$ & $35 \%$ & $55 \%$ & $47 \%$ & & $81 \%$ \\
\hline
\end{tabular}




\section{Table 2 (on next page)}

Shannon values for $18 \mathrm{~S}$ and $\mathrm{COI}$, as well as biotic index values for COI only.

Data is given as the range and median (in parenthesis) of individual sample values ( $n=5$ ) for individual extract and pooled extracts per sediment sample. Shannon values are given separately for each grab, while biotic index values represent the range in the entire threegrab dataset. 
1 Table 2. Shannon values for $18 \mathrm{~S}$ and COI, as well as biotic index values for COI only. Data is 2 given as the range and median (in parenthesis) of individual sample values $(\mathrm{n}=5)$ for individual 3 extract and pooled extracts per sediment sample. Shannon values are given separately for each 4 grab, while biotic index values represent the range in the entire three-grab dataset.

5

\begin{tabular}{|lllll|}
\hline & $\begin{array}{l}\text { 18S } \\
\text { Individual extracts }\end{array}$ & Pooled extract & $\begin{array}{l}\text { COI } \\
\text { Individual extracts }\end{array}$ & Pooled extract \\
\hline Shannon & & & & \\
Grab 1 & $4,86-(5,12)-5,25$ & $5,35-(5,76)-6,15$ & $0,15-(0,34)-1,31$ & $0,68-(1,69)-3,47$ \\
Grab 2 & $5,20-(6,01)-6,49$ & $6,30-(6,40)-6,86$ & $2,89-(3,97)-4,30$ & $0,88-(3,98)-4,49$ \\
Grab 3 & $6,06-(6,16)-6,30$ & $6,14-(6,25)-6,46$ & $2,86-(3,19)-4,24$ & $1,70-(3,85)-4,66$ \\
Total & $4,86-(6,01)-6,49$ & $5,35-(6,25)-6,86$ & $0,15-(3,17)-4,30$ & $0,68-(3,42)-4,66$ \\
\hline & & & & \\
\hline Biotic indices & & & & \\
gAMBI & & & $0,99-(1,54)-2,99$ & $0,19-(1,86)-2,98$ \\
(pa)gAMBI & & & $0,50-(0,79)-1,15$ & $0,47-(0,75)-1,50$ \\
ISI2012 & & & $20,14-(9,42)-10,40$ & $9,07-(9,30)-10,06$ \\
NSI2012 & & & $0,54-(0,70)-0,75$ & $0,58-(0,67)-0,80$ \\
NQI & & &
\end{tabular}

6 
Figure 1

Study sampling design.

(A) Five separate $50 \mathrm{~g}$ sediment samples each were taken from three grab parallels at the offshore monitoring station GK-DA-01. (B) Each sediment sample $(n=15)$ was stirred by hand before subsampling five $0.5 \mathrm{~g}$ sediment PowerSoil DNA extracts $(n=75)$. DNA extracts from one sediment sample per grab (marked with an asterisk) were sequenced separately to investigate intra-sediment sample heterogeneity ( $n=3 * 5$ per marker). To examine heterogeneity within and between grabs, the five DNA extracts from each sediment sample were pooled prior to PCR and sequencing ( $n=3 * 5$ per marker).

A

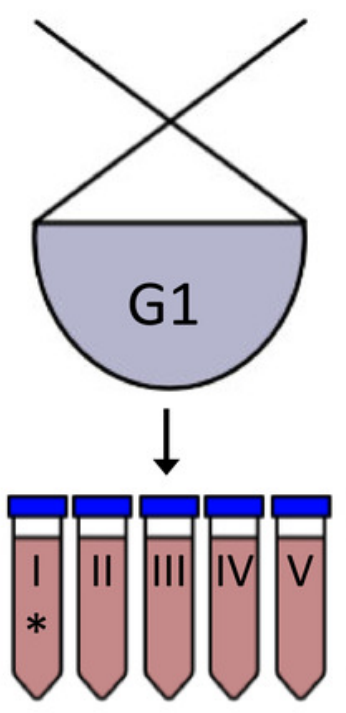

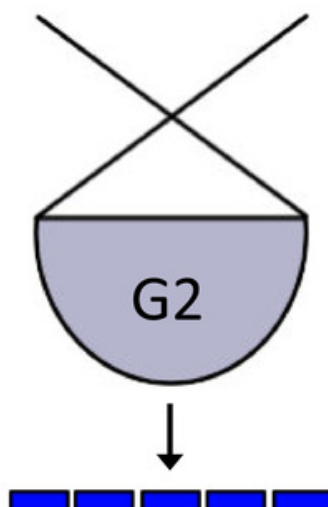

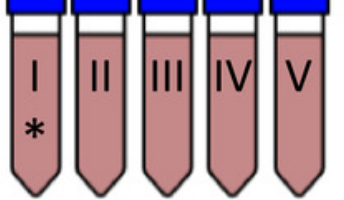

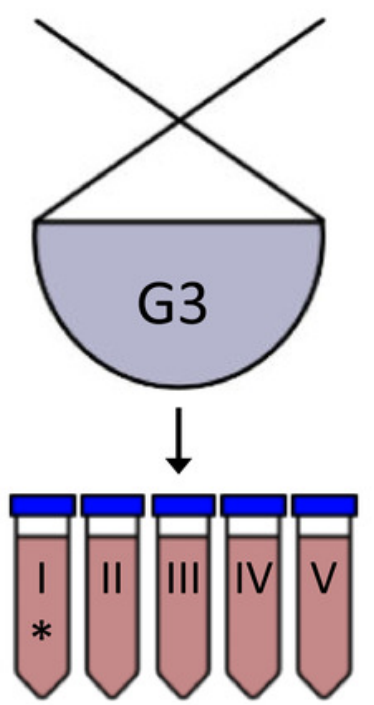

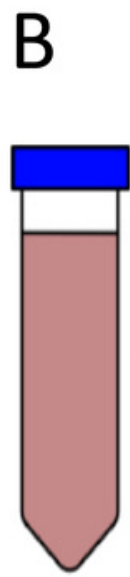

Pooled 5-extract sequencing for each sediment subsample (I-V, $n=3 * 5)$.

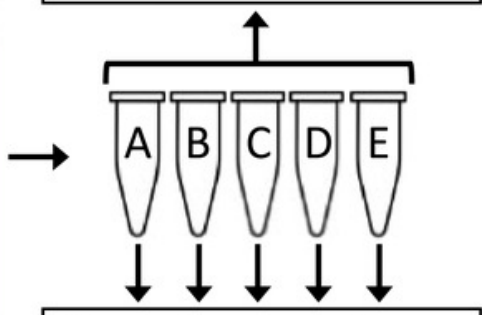

*Separate sequencing per extract for one sediment subsample per grab (IAE, $n=3 * 5$ ). 
Figure 2

Dataset read abundance.

Read abundance and the most abundant OTUs for (A) all 18S metabarcoding data and (B) COI phylum level or lower metabarcoding data at sediment sample (I-V) and individual extract $(A-E)$ level for the entire three-grab dataset. 


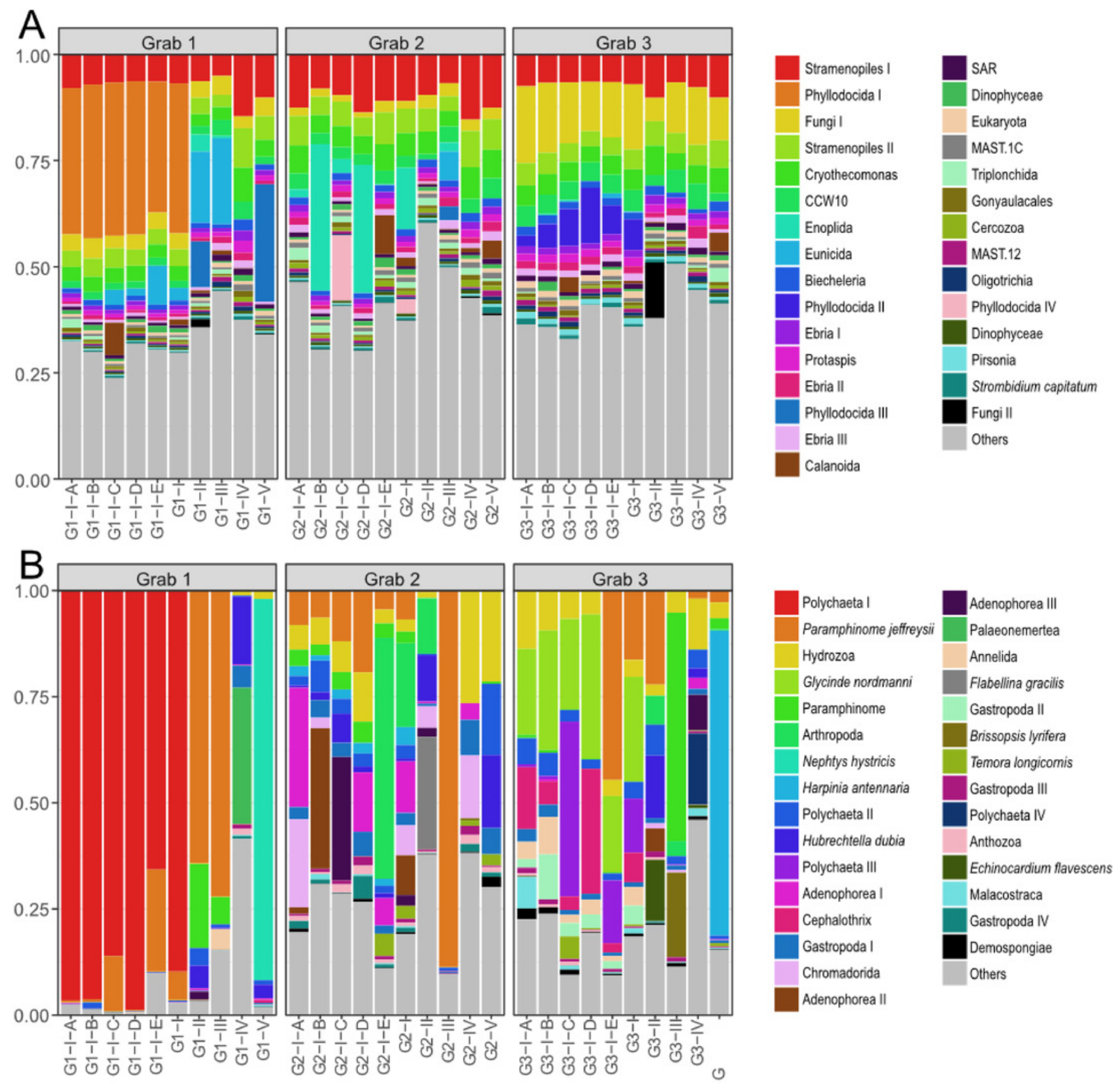




\section{Figure 3}

Sample beta diversity.

Boxplots of (A) 185 and (C) COI pairwise dissimilarities for individual extracts within one sediment sample from each grab, pooled extracts from each sediment sample from each grab, and between each grab. Dots are individual datapoints, and red dots dataset outliers. NMDS analysis showing relative (B) 185 and (D) COI pairwise distances at individual extract and pooled extract (sediment sample) level. 

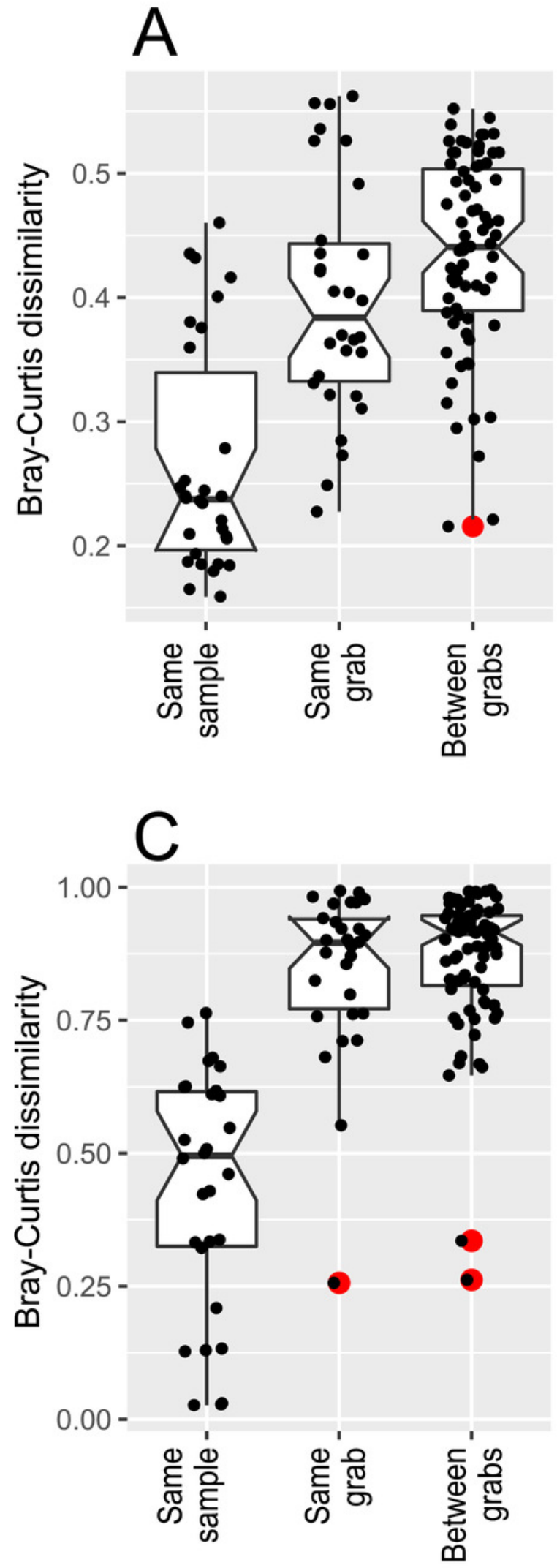
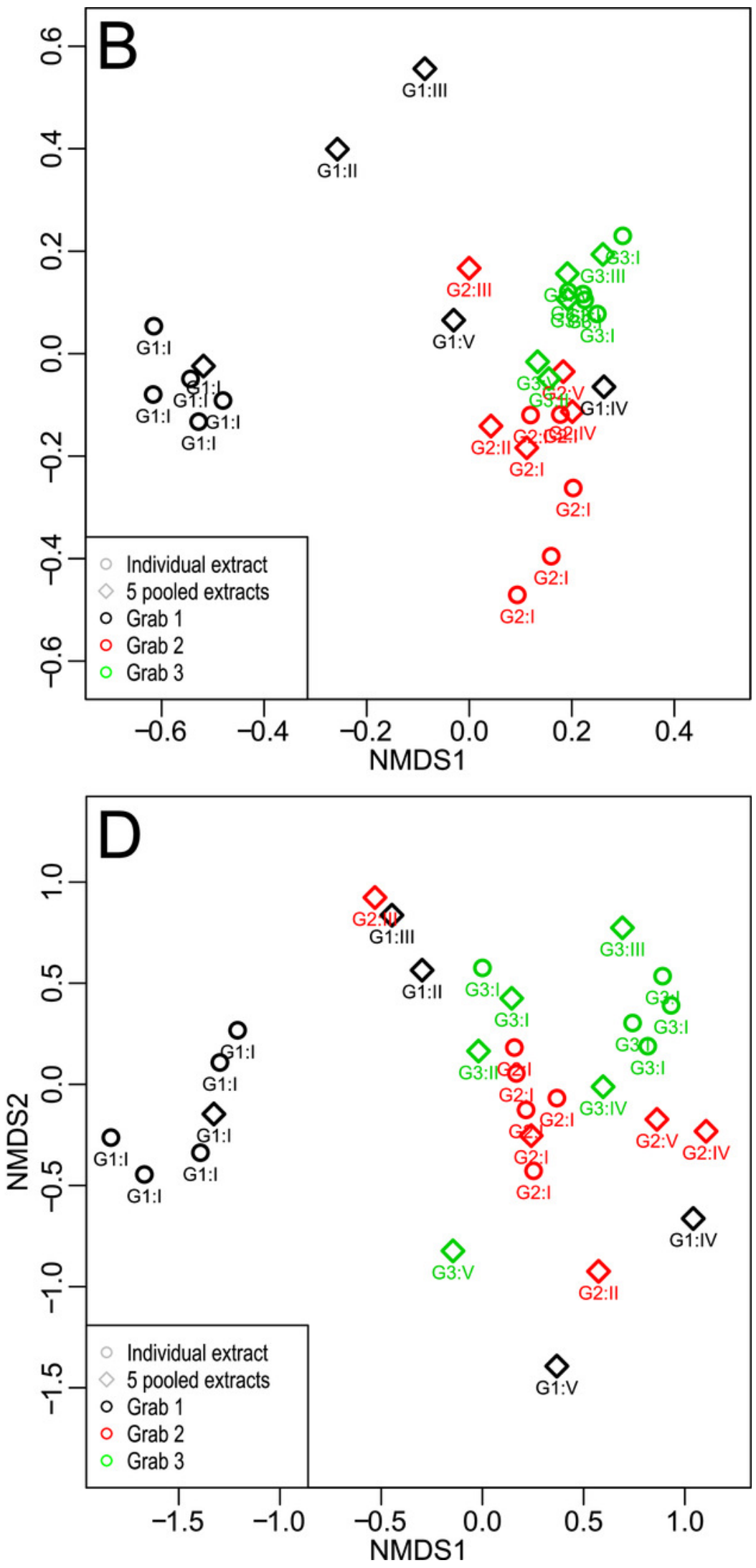
Figure 4

Grab level OTU coverage.

Euler diagrams of (A) $18 \mathrm{~S}$ and (B) COI OTUs at grab level, showing the number of unique and shared OTUs for both markers.
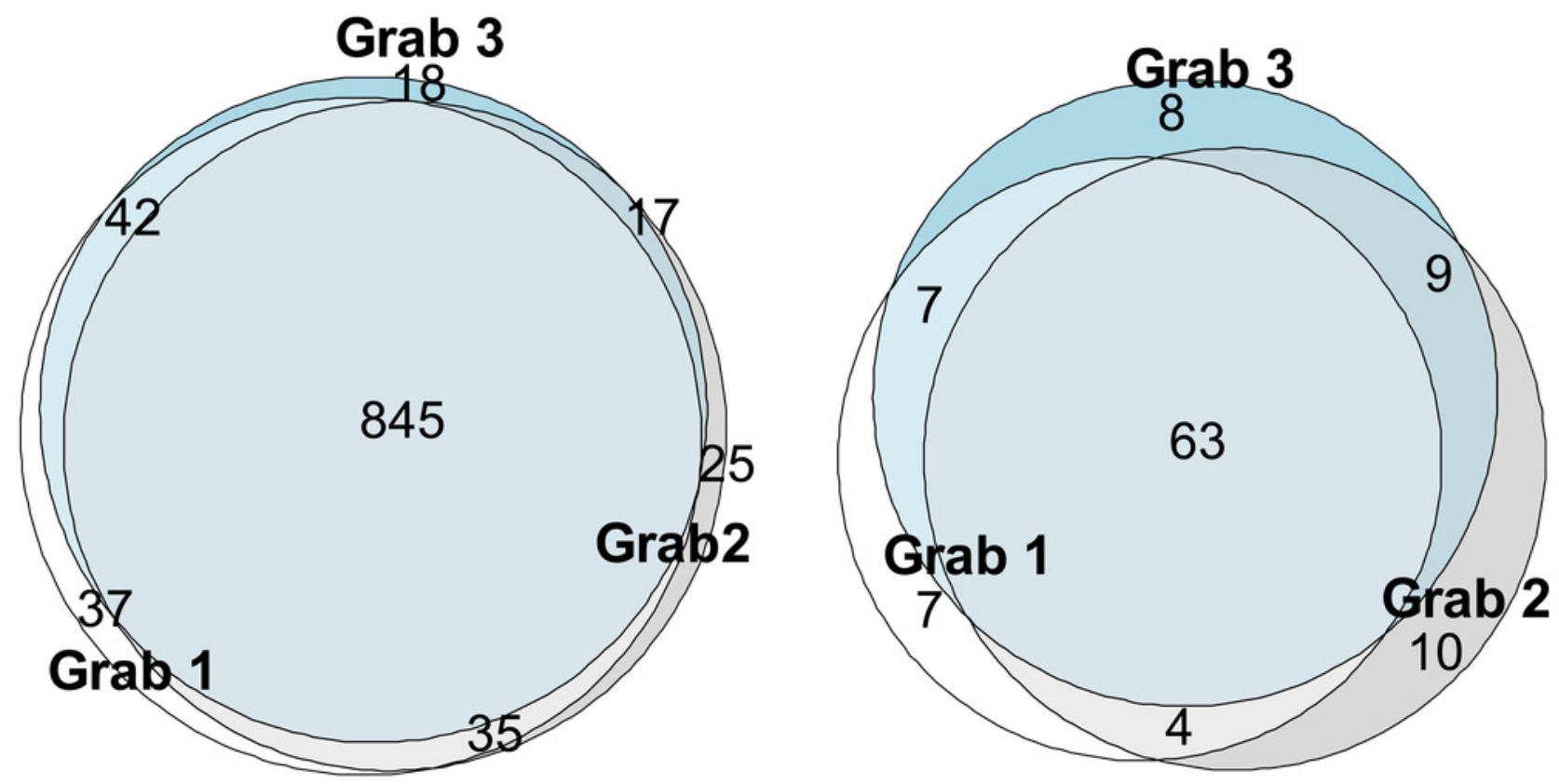
Figure 5

OTU aggregation curves.

OTU aggregation curves. Median $18 \mathrm{~S}(\mathrm{~A}-\mathrm{C})$ and $\mathrm{COI}(\mathrm{D}-\mathrm{F})$ richness increase for individual extracts $(A, D)$, and sediment samples per grab $(B, E)$ shown separately for grabs $1-3$, and as cumulative total grab data for the whole dataset (C, F).
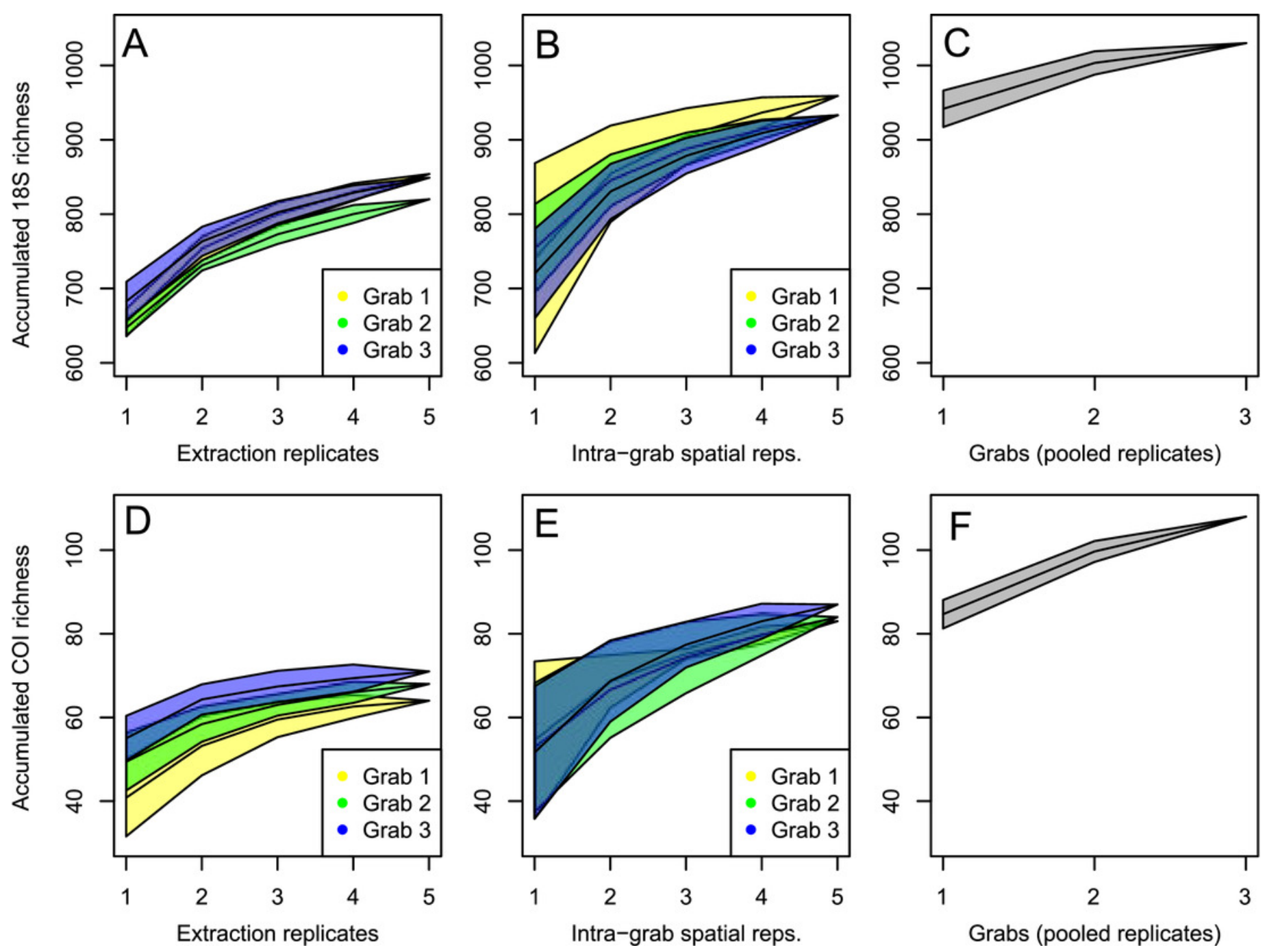